\title{
Nanoplasmonic Sensing and Capillary Electrophoresis for Fast Screening of Interactions between Phosphatidylcholine Biomembranes and Surfactants
}

\author{
Filip Duša, ${ }^{* \dagger}$ Wen Chen, ${ }^{\ddagger}$ Joanna Witos, ${ }^{\S \odot}$ and Susanne K. Wiedmer* ${ }^{* \ddagger}$ \\ ${ }^{\dagger}$ Institute of Analytical Chemistry of the Czech Academy of Sciences, Veveři 97, 60200 Brno, Czech Republic \\ ${ }^{\ddagger}$ Department of Chemistry, University of Helsinki, P.O. Box 55, FIN-00014 University of Helsinki, Helsinki, Finland \\ ${ }^{\S}$ Department of Bioproducts and Biosystems, Aalto University, P.O. Box 16300, FIN-00076 Espoo, Finland
}

Supporting Information

\begin{abstract}
Nanoplasmonic sensing (NPS), based on localized surface plasmon resonance, with sensors composed of glass covered with golden nanodisks and overlaid with a $\mathrm{SiO}_{2}$ coating was applied in this study. Egg phosphatidylcholine (eggPC), being an easily accessible membrane-forming lipid, was used for preparation of biomimicking membranes. Small unilamellar vesicles with an approximate hydrodynamic diameter of $30 \mathrm{~nm}$, formed by sonication in 4-(2hydroxyethyl)piperazine-1-ethanesulfonic acid buffer, were adsorbed within $10 \mathrm{~min}$ on the sensor surface either as intact vesicles or as a planar bilayer. The adsorbed biomembrane systems were further utilized for interaction studies with four different well-known surfactants (negatively and positively

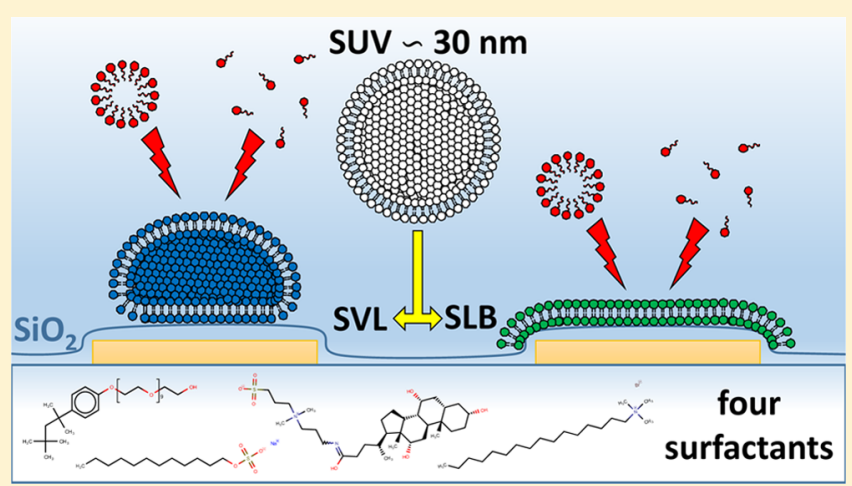
charged, zwitterionic, and nonionic) and each surfactant was tested at concentrations below and above the critical micelle concentration (CMC). Our results allowed the evaluation of different NPS patterns for every particular supported membrane system, surfactant, and its concentration. The most significant effect on the membrane was achieved upon the introduction of zwitterionic surfactant micelles, which in fact completely solubilized and removed the lipid membranes from the sensor surface. Other surfactant micelles interacted with the membranes and formed mixed structures remaining on the sensor surface. The studies performed at the concentrations below the CMCs of the surfactants showed that different mixed systems were formed. Depending on the supported membrane system and the type of surfactant, the mixed systems indicated different formation kinetics. Additionally, the final water rinse revealed the stability of the formed systems. To investigate the effect of the studied surfactants on the overall surface charge of the biomembrane, capillary electrophoresis (CE) experiments were carried out in parallel with the NPS analysis. The electroosmotic flow mobility of an eggPC-coated fused silica capillary was used to measure the total surface charge of the biomembrane after its treatment with the surfactants. Our results indicated in general good correlation between CE and NPS data. However, some discrepancies were seen while applying either zwitterionic or positively charged surfactants. This confirmed that $\mathrm{CE}$ analysis was able to provide additional data about the investigated systems. Taken together, the combination of NPS and CE proved to be an efficient way to describe the nature of interactions between biomimicking membranes and amphiphilic molecules.
\end{abstract}

\section{INTRODUCTION}

The cellular membrane is one of the key cellular organelles, which not only separates the inner environment of a cell from the surrounding medium but also plays a crucial role in many biochemical processes. Therefore, a method that could determine the dynamics of membrane interaction would enable fast prescreening of newly synthesized amphiphilic substances. Egg L- $\alpha$-phosphatidylcholine (eggPC) is a highly available phospholipid, which can provide biomembrane-mimicking platforms for studying interactions with analytes. ${ }^{1}$ Depending on the surface investigated, eggPC can remain as intact adsorbed vesicles or supported lipid bilayers (SLBs) on surfaces. ${ }^{2,3}$ A newly emerging technique for studying surface interactions is nanoplasmonic sensing (NPS), which is based on localized surface plasmon resonance (LSPR).$^{4-7}$ It can provide insight into a number of different changes happening within the sensing region. ${ }^{5,8}$ The sensitivity to changes of refractive index (RI) is confined to the region localized near to the metal nanostructures on the sensor's surface, with a decay depth of a few tens of nanometers from the nanostructures. ${ }^{9}$ This is a particular benefit of NPS compared with competing techniques where bulk liquid is sensed at sensing depths of hundreds of

Received: April 3, 2018

Revised: April 30, 2018

Published: May 1, 2018 
nanometers. Moreover, the sensitivity of NPS to observe changes in the RI enable the methodology to neglect any entrapped solution having the same RI as that of the bulk (particularly in the case of adsorbed vesicles) and also to detect structural changes of the biomembranes. ${ }^{7}$ This is very important in regard to calculation of adsorption and vesicle deformation parameters. ${ }^{10}$ Capillary electrophoresis (CE) was applied as a complementary method to provide an overview on the net surface charge of phospholipid-coated capillary and to provide quantitative data on the interactions of compounds with polymer/protein/lipid-coated capillary surfaces. ${ }^{11-13}$

For this study, we selected four different well-known surfactants at two concentrations, one below and one above the critical micelle concentration (CMC), and allowed these to interact with SLBs or supported vesicle layers (SVLs) composed of eggPC. The surfactants were nonionic 4(1,1,3,3-tetramethylbutyl)phenyl-poly(ethylene glycol) (Triton $\mathrm{X}-100)$, negatively charged sodium dodecyl sulfate (SDS), zwitterionic 3-[(3-cholamidopropyl)dimethylammonio]-1-propanesulfonate (CHAPS), and positively charged cetyltrimethylammonium bromide (CTAB) (the structures are shown in Supporting Information S1).

The different ionic nature of every surfactant system gives the rationale to investigate the interaction mechanisms by NPS, which is capable of detecting structural changes in a strictly confined sensing space of approximately $10 \mathrm{~nm} .^{14}$ To fully exploit the sensing depth of NPS, sonication was used to prepare liposomes of very small diameter $(30 \mathrm{~nm})$. CE was used for analysis of the electroosmotic flow (EOF) mobility to obtain further information about the overall net charge of the sensed surface (i.e., capillary). 4-(2-Hydroxyethyl)piperazine-1ethanesulfonic acid (HEPES) buffer at $\mathrm{pH} 7.4$ along with silicon dioxide $\left(\mathrm{SiO}_{2}\right)$-coated NPS sensors was chosen to obtain equivalent results from NPS and CE (the same buffer and fused silica capillary was used in $\mathrm{CE}$ ). On the basis of the acquired information, the data presented here further aims at giving a basis for future analysis of any possible disruptive/ altering effects of amphiphilic compounds on biomembranes.

\section{MATERIALS AND METHODS}

Chemicals. EggPC (Egg, Chicken) was purchased from Avanti Polar Lipids (Alabaster, AL). CHAPS (purity of 98\%), nitric acid, Triton X-100, and SDS (purity of 99\%) were obtained from Sigma (Darmstadt, Germany). Calcium chloride, ethylene glycol, HEPES, and high-pressure liquid chromatography-grade methanol were from VWR International Oy (Espoo, Finland). Sodium hydroxide pellets were purchased from J.T. Baker Chemicals (Center Valley, PA). The $\mathrm{pH}$ calibration solutions (7.0 and 10.0) were obtained from Merck (Darmstadt, Germany). Distilled water was further purified with a Millipore water-purification system (Millipore, Molsheim, France).

Buffer Preparation. Concentrations of HEPES and $\mathrm{NaOH}$ were calculated with PeakMaster $5.1^{15}$ (available for free at http://web. natur.cuni.cz/gas/) to obtain a buffer solution of $\mathrm{pH} 7.4$ and ionic strength of $10 \mathrm{mM}$. Appropriate amounts of both components were weighted, and the $\mathrm{pH}$ of the resulting solution was measured to check if $\mathrm{pH}$ was within the tolerated limit of $\pm 0.05 \mathrm{pH}$ units. For SLB analysis, a $500 \mathrm{mM}$ stock solution of $\mathrm{CaCl}_{2}$ was diluted in HEPES buffer to have a final concentration of $5 \mathrm{mM}$. All of the solutions were filtered through a poly(tetrafluoroethylene) syringe filter with $0.45 \mu \mathrm{m}$ pore size (Gelman Sciences, Ann Arbor, MI).

Vesicle Preparation. An appropriate amount of eggPC stock solution in chloroform at a concentration of $25 \mathrm{mg} / \mathrm{mL}(32.46 \mathrm{mM})$ was used for preparing the vesicles. The chloroform was evaporated under a gentle stream of air, which was followed by overnight evacuation in a desiccator. The thin lipid film was rehydrated with
HEPES buffer to a final concentration of $4 \mathrm{mM}$ of eggPC and shaken continuously for $60 \mathrm{~min}$ at $60^{\circ} \mathrm{C}$. The multilamellar vesicle dispersion was sonicated at $37 \mathrm{kHz}$ and $100 \%$ power for $20 \mathrm{~min}$ in an ultrasonic bath ELMASONIC P $30 \mathrm{H}$ (Elma, Singen, Germany) to produce small unilamellar vesicles (SUVs). The tank was half-filled with distilled water to intensify the power of ultrasound, and the temperature of water was kept below $35{ }^{\circ} \mathrm{C}$. The eggPC SUV dispersion was further filtered through a syringe filter of $0.45 \mu \mathrm{m}$ pore size to remove any dust particles. The size distribution of every SUV batch was checked with Zetasizer Nano ZS instrument (Malvern Instruments, Malvern, U.K.). One run consisted of 14 individual measurements, and every result was produced as a mean value of seven runs. For vesicle size evaluation, we used distribution of size by volume option.

NPS Measurements. NPS measurements based on LSPR were conducted on nanodisks in optical transmission mode using an Insplorion XNano II instrument (Insplorion $\mathrm{AB}$, Gothenburg, Sweden). ${ }^{10}$ The NPS signal was recorded at $1 \mathrm{~Hz}$ frequency. Silicon dioxide-coated $(\sim 10 \mathrm{~nm})$ sensor chips (Insplorion $\mathrm{AB}$, Gothenburg, Sweden) were used as sensing surfaces. Every sensor was treated for 20 min with oxygenation using a UV ozone cleaner (UVC-1014 NanoBioAnalytics, Berlin, Germany) prior to its first use. Before the real experiments, the property of each sensor was checked by determining the bulk refractive index sensitivity using ethylene glycol/ water mixtures. Between the experiments, the sensor was cleaned in methanol by gentle sonication at $80 \mathrm{kHz}$ and $30 \%$ power in sweep mode for $5 \mathrm{~min}$. Every sensor was reused until the maximum extinction of the sensor decreased below $80 \%$ of its original value. All experiments were performed twice under continuous flow $(100 \mu \mathrm{L} /$ min) controlled by a Reglo-CPF Digital peristaltic pump (Ismatec, Wertheim, Germany) at $25{ }^{\circ} \mathrm{C}$ (thermostated temperature). All solutions were thoroughly sonicated and vacuum degassed before they were introduced into the measurement chamber. Data was collected with the Insplorer version 1.2 software (Insplorion $\mathrm{AB}$, Gothenburg, Sweden) and evaluated by OriginPro 8.6 software (OriginLab, Northampton, MA).

Capillary Electrophoresis. Agilent $7100 \mathrm{CE}$ system from Agilent Technologies (Santa Clara, CA) equipped with a UV-vis diode array detector was used for all CE experiments. Fused silica capillaries with $50 \mu \mathrm{m}$ i.d. and $365 \mu \mathrm{m}$ o.d. were from Polymicro Technologies (Phoenix, AZ). Prior to CE measurements, the capillary was cut to $48.5 \mathrm{~cm}$ and the external polyimide layer burned at $8.5 \mathrm{~cm}$ from the outlet end to obtain a detection window (effective length of $40 \mathrm{~cm}$ ). A pressure of $935 \pm 5$ mbar was used for all flushing steps. The CE capillary cartridge was thermostated to $25^{\circ} \mathrm{C}$ during all measurements and conditioning steps. Each new capillary was first conditioned with 1 $\mathrm{M} \mathrm{NaOH}$ for $10 \mathrm{~min}$, which was followed by a rinse with water for 10 min and with HEPES buffer for $10 \mathrm{~min}(\mathrm{pH}=7.4,10 \mathrm{mM}$ ionic strength). A water solution of $0.5 \mathrm{mM}$ thiourea was used as an electroosmotic flow (EOF) mobility marker. The EOF marker was injected into the capillary by applying a pressure of $10 \mathrm{mbar}$ for $10 \mathrm{~s}$. Next, the separation voltage was applied for $10 \mathrm{~min}$ at $25 \mathrm{kV}$. Before EOF mobility run, the capillary was rinsed for 2.5 min with HEPES buffer. The EOF mobility was measured on uncoated fused silica capillary, on eggPC-coated capillary, and after application of a surfactant on a liposome-coated layer.

EggPC liposomes were utilized as a semipermanent capillary coating agent, following a slightly modified protocol developed by Kuldvee et al. ${ }^{16}$ Briefly, the capillary was first rinsed for 10 min with $2 \mathrm{M} \mathrm{HNO}_{3}$ (Kuldvee et al. used $0.5 \mathrm{M} \mathrm{HNO}_{3}$ ), followed by a 20 min rinse with water, and a $10 \mathrm{~min}$ rinse with $0.75 \mathrm{mM}$ eggPC. The system was then left to equilibrate for $15 \mathrm{~min}$ with the eggPC vesicle dispersion inside the capillary. The eggPC coating was regenerated after every interaction study with every concentration of a surfactant by running a complete eggPC coating procedure. The EOF mobility was measured five times before and after a rinse with a surfactant. Every surfactant was applied at two concentrations; one below and one above the CMC. The rinsing method included a $10 \mathrm{~min}$ water rinse, followed by a $10 \mathrm{~min}$ surfactant rinse, and a final $10 \mathrm{~min}$ water rinsing step. The EOF mobility $\left(\mu_{\mathrm{EOF}}\right)$ was calculated according to eq 1 and 



Figure 1. Change in the peak shift (shift of maximum-extinction wavelength) as a function of time for $0.15 \mathrm{mM}$ sonicated eggPC SUVs after adsorption onto a $\mathrm{SiO}_{2}$-coated NPS sensor in two different forms of supported lipids (consisting of two repetitions of each, denoted as no. 1 and 2 in both graphs). (A) Pretreatment: 5 min of water, 5 min of HEPES buffer pH $7.4(I=10 \mathrm{mM})$ containing $5 \mathrm{mM} \mathrm{CaCl}{ }_{2}$; the plot shows SLB formation during $5 \mathrm{~min}$ of application of $0.15 \mathrm{mM}$ SUV in HEPES buffer $\mathrm{pH} 7.4(I=10 \mathrm{mM})$ containing $5 \mathrm{mM} \mathrm{CaCl}_{2}$. (B) Pretreatment: 5 min of water, 5 min of $2 \mathrm{M} \mathrm{HNO}_{3}$, and $10 \mathrm{~min}$ of water; the plot shows adsorption of intact SUVs during $10 \mathrm{~min}$ of application of $0.15 \mathrm{mM}$ SUVs in HEPES buffer pH $7.4(I=10 \mathrm{mM})$. All measurements were carried out under continuous flow at a flow rate of $100 \mu \mathrm{L} / \mathrm{min}$. Insets with first-order derivatives were made using OriginPro 8.6 plotting software. (The $\sim 1$ min delay of signal response in the plot compared with the change of the solution by time schedule was caused by $\sim 100 \mu \mathrm{L}$ of dead volume of delivering tube.)

presented as a mean value of five runs along with the relative standard deviation (RSD).

$$
\mu_{\mathrm{EOF}}=\frac{L_{\mathrm{eff}} \cdot L_{\mathrm{tot}}}{t_{\mathrm{EOF}} \cdot V}
$$

$\mu_{\mathrm{EOF}}$ stands for the electroosmotic flow mobility, $L_{\text {eff }}$ is the effective length of the capillary, $L_{\text {tot }}$ is the total length of the capillary, $t_{\mathrm{EOF}}$ is the migration time of the EOF marker peak maximum, and $V$ stands for the voltage applied during analysis.

\section{RESULTS AND DISCUSSION}

Hydrodynamic Diameters of eggPC Vesicles. Sonication of the eggPC liposome dispersion for $20 \mathrm{~min}$ at $37 \mathrm{kHz}$ and room temperature produced a clear solution. To determine the sizes (hydrodynamic diameters) of the liposomes, dynamic light scattering measurements were conducted. The volumebased size distribution revealed two distinct peaks with average diameters of $35.2 \pm 11.0$ and $167.9 \pm 70.8 \mathrm{~nm}$ (average of all liposome sonication batches). The population of the smaller liposomes was $82.4 \pm 9.1 \%$. It should be noted that the population of the bigger liposomes $(14.3 \pm 7.0 \%)$ was roughly the same regardless of prolonged sonication (data not shown). The size varied highly from batch to batch, suggesting that either there was an equilibrium for such distribution of size or there were some dust particles that were not removed by filtering through a $0.45 \mu \mathrm{m}$ filter. When the number-based distribution was investigated, the population of small liposomes was $99 \%$. This would further prove our hypothesis that the second size was probably caused by contamination with small dust particles. It is also evident that the preparation of liposome vesicles utilizing only sonication is an economic method and it does not require any other instruments than an ultrasonic bath, which is available in most analytical labs. Moreover, a model of vesicle adsorption, which was described by Jackman et al, showed that the time needed for vesicles to reach low and moderate surface coverages scaled with $r^{-5 / 3}(r$ : vesicle hydrodynamic radius). ${ }^{10}$ Therefore, using very small vesicles decreases the overall time needed for coating.
Interaction between eggPC and the $\mathrm{SiO}_{2}$ Sensor. Our recent studies have shown that negatively charged liposomes can adsorb on titanium dioxide $\left(\mathrm{TiO}_{2}\right)$ - and silicon nitride $\left(\mathrm{Si}_{3} \mathrm{~N}_{4}\right)$-coated sensors using HEPES buffer $(\mathrm{pH}$ 7.4; $I=10$ $\mathrm{mM}) .{ }^{17}$ Therefore, prior to immobilization with liposomes, the sensor was pretreated for $20 \mathrm{~min}$ by UV ozonization to remove any organic contaminants from the surface. However, the UVozonized $\mathrm{SiO}_{2}$ sensor was unable to bind either intact eggPC liposomes or form SLBs when vesicles were prepared in HEPES buffer at $\mathrm{pH}$ 7.4. Moreover, $\mathrm{UV}$ ozonization of the $\mathrm{SiO}_{2}$ sensor caused a serious hysteresis effect, evidenced by drifting of the peak shift. It took more than $3 \mathrm{~h}$ to stabilize the NPS signal. Hence, gentle sonication of the $\mathrm{SiO}_{2}$ sensor immersed in methanol for $5 \mathrm{~min}$ was used to regenerate the sensor surface between the measurements. With such a procedure, drifting of the signal took on average only $15 \mathrm{~min}$, considerably shortening the total analysis time. The bulk RI sensitivity was analyzed for every new sensor using ethylene glycol solutions of increasing mass concentration. The bulk RI sensitivity for the three sensors used throughout the study had slopes of 102.8, 102.5, and $102.2 \mathrm{~nm}$ per RI unit, respectively (see Supporting Information S2). Furthermore, on the basis of $\mathrm{CE}$ analysis of the EOF mobility, we can conclude that the overall surface charge of silica is negative using a HEPES at $\mathrm{pH} 7.4$ buffer.

Addition of Calcium to the HEPES Buffer. The SLB was formed very fast when $5 \mathrm{mM} \mathrm{CaCl}{ }_{2}$ was added to the HEPES buffer (see Figure 1A). The NPS peak shift typically stabilized within 5 min by rinsing the sensor with the SUV dispersion in $\mathrm{HEPES} / \mathrm{CaCl}_{2}$ buffer. The effect of adding calcium ions to $1,2-$ dioleoyl-sn-glycero-3-phosphocholine (DOPC) SUVs adsorbing on $\mathrm{SiO}_{2}$-coated NPS was thoroughly studied by Dacic et al. ${ }^{18}$ SLB formation was further confirmed by the first-order time derivative of the maximum extinction showing a second peak, which is characteristic for the formation of SLBs from intact vesicles (see Figure 1A inset). The beginning of the second peak signatures the critical surface SUV coverage of approximately $30 \%$, where vesicles start to break down and form SLBs. The process of SLB formation on $\mathrm{SiO}_{2}$ has been 

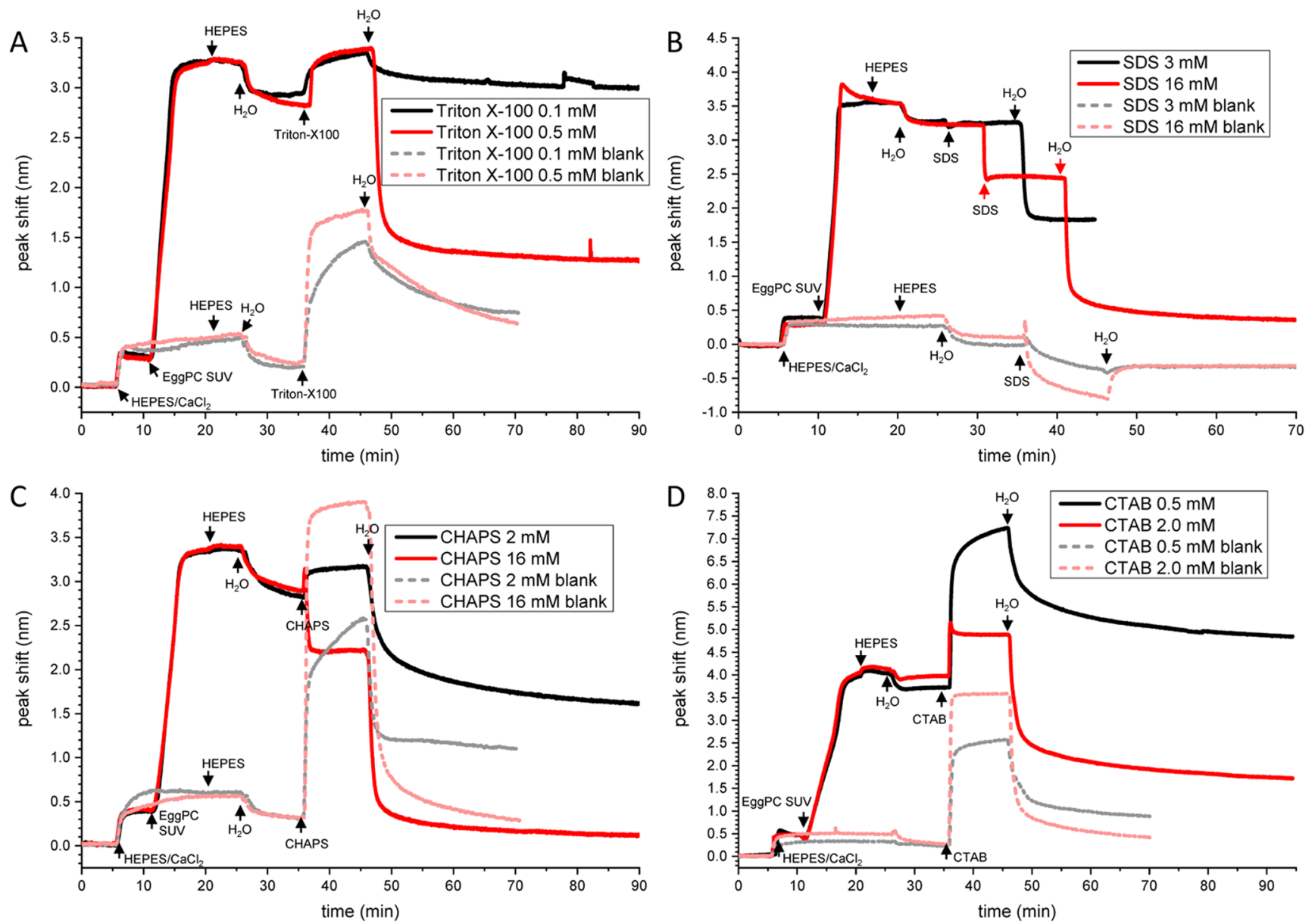

Figure 2. Change in the peak shift (shift of maximum-extinction wavelength) as a function of time for eggPC SLB-coated SiO ${ }_{2} \mathrm{NPS}_{\text {sensors }}$ (black for unimers and red for micelles). Blank measurements of the surfactants are also shown as dashed lines with lighter colors (gray for unimers and light red for micelles), which were measured on the bare sensor without eggPC membrane. One repetition out of two is shown for easier presentation. All changes of solutions are marked by arrows with a description (A) interaction of 0.1 and $0.5 \mathrm{mM}$ Triton X-100 with SLB on bare $\mathrm{SiO}_{2}$-coated sensor; (B) interaction of 3 and $16 \mathrm{mM}$ SDS with SLB on bare $\mathrm{SiO}_{2}$-coated sensor; (C) interaction of 2 and $16 \mathrm{mM}$ CHAPS with SLB on bare $\mathrm{SiO}_{2}$-coated sensor; (D) interaction of 0.5 and $2.0 \mathrm{mM} \mathrm{CTAB}$ with SLB on bare $\mathrm{SiO}_{2}$-coated sensor.

described by Reimhult et al. ${ }^{19,20}$ and was studied using LSPR by Jonsson et al.?

The fast formation of SLB substantially decreased the time needed for preparing a sensor surface for interaction studies. The SLB by its nature is more durable against applied stress since it forms one compact layer following the topology of the sensor surface. Intact adsorbed vesicles are more prone to stress because their spherical structure can break up, in contrast to SLBs. Hence, we utilized both supported lipid forms (i.e., SVL and SLB) to obtain more complete data about the interactions between the surfactants and the studied membranes.

Pretreatment with Nitric Acid. To attach intact vesicles on $\mathrm{SiO}_{2}$, a sodium hydroxide rinse was used before the HEPES buffer without $\mathrm{CaCl}_{2}$. However, there was no interaction between eggPC liposomes and the $\mathrm{SiO}_{2}$ surface. Our results are opposite to the recently published NPS studies, where a $\mathrm{Si}_{3} \mathrm{~N}_{4}$ coated sensor with the same pretreatment conditions was successfully used for vesicle immobilization. ${ }^{17}$ Moreover, sodium hydroxide considerably lowered the level of the NPS peak maximum extinction (in water) after every application. This suggests deterioration of the $\mathrm{SiO}_{2}$ coating, and indeed the sensor was rendered unusable after a few runs with such a treatment. Adsorption of SVLs was obtained by adopting a nitric acid $\left(\mathrm{HNO}_{3}\right)$ pretreatment method, developed for immobilizing phospholipid vesicles on fused silica capillaries for capillary electrochromatography. ${ }^{16,21}$ Compared with $0.5 \mathrm{M}$ $\mathrm{HNO}_{3}$ used in the mentioned references, $2 \mathrm{M} \mathrm{HNO}_{3}$ was applied for pretreating the NPS sensor to more efficiently remove ionic species prior to the preceding NPS analysis. The sensor surface was rinsed with $2 \mathrm{M} \mathrm{HNO}_{3}$ for $5 \mathrm{~min}$, and after a short water rinse, the SUVs were adsorbed on the surface as SVLs (see Figure 1B). The first-order time derivative of the peak shift showed no evidence for SLB formation (see Figure $1 \mathrm{~B}$ inset). More importantly, no deterioration of the $\mathrm{SiO}_{2}$ coating (as when rinsing with $0.1 \mathrm{M} \mathrm{NaOH}$ ) was observed; therefore, the sensor gave repeatable signals for up to a few tens of runs. Coating of the sensor took $10 \mathrm{~min}$, which was twice as long as that for the formation of the SLBs. Such short adsorption times, which were obtained by using very small sonicated vesicles, in combination with short cleaning and stabilization times, saved a significant amount of time needed for the preparation of the biosensing surface.

Rate of Adsorption. Recently, it was shown that the adsorption rate is faster when divalent cations are present in the solution. ${ }^{18}$ This correlates well with the obtained results on the rates of adsorption at low saturation of the surface, giving rates of $3.04 \pm 0.91$ and $2.09 \pm 0.25 \mathrm{~nm} / \mathrm{min}$ for SLB and SVL formation, respectively. The average peak shift values were 2.95 

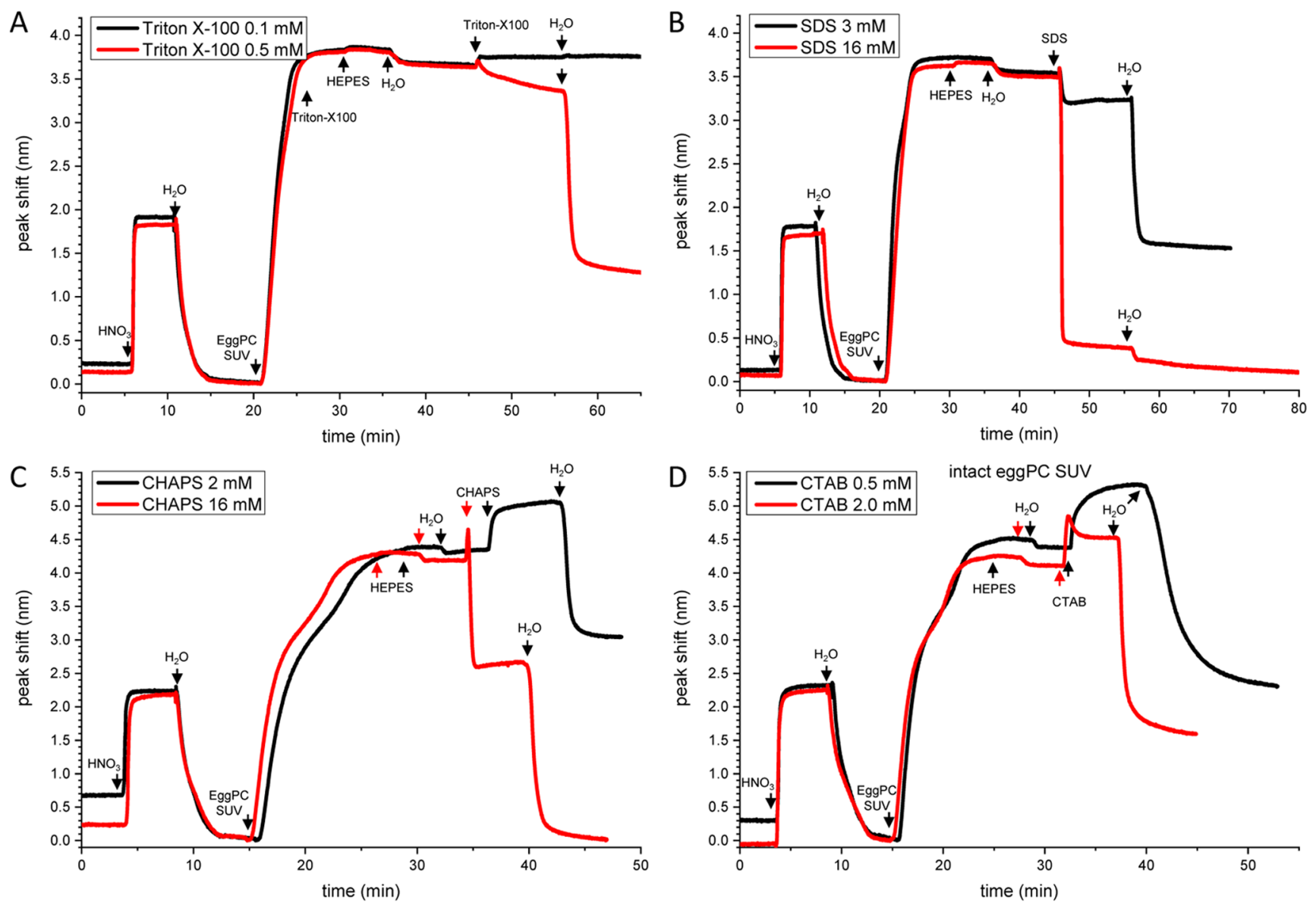

Figure 3. Change in the peak shift (shift of maximum-extinction wavelength) as a function of time for eggPC SVL-coated $\mathrm{SiO}_{2} \mathrm{NPS}_{\text {sensors }}(\mathrm{black}$ for unimers and red for micelles). One repetition out of two is shown for easier presentation. All changes of solutions are marked by arrows with a description: (A) interaction of 0.1 and $0.5 \mathrm{mM}$ Triton X-100 with SVL on bare $\mathrm{SiO}_{2}$-coated sensor; (B) interaction of 3 and $16 \mathrm{mM}$ SDS with SVL on bare $\mathrm{SiO}_{2}$-coated sensor; (C) interaction of 2 and $16 \mathrm{mM}$ CHAPS with SVL on bare $\mathrm{SiO}_{2}$-coated sensor; (D) interaction of 0.5 and $2.0 \mathrm{mM}$ $\mathrm{CTAB}$ with $\mathrm{SVL}$ on bare $\mathrm{SiO}_{2}$-coated sensor.

\pm 0.03 and $3.81 \pm 0.01 \mathrm{~nm}$ for SLB and SVL formation, respectively. The higher peak shift of SVL suggests a higher packing ability due to very small vesicles sizes. It has been shown earlier that the peak shift time derivative for small vesicles $(58 \mathrm{~nm})$ agrees well with the diffusion-limited adsorption of nondeformable vesicles. ${ }^{10}$ It can be predicted that the liposomes used in our study follow the same adsorption kinetics. Moreover, the same study showed that $58 \mathrm{~nm}$ sized nondeformed vesicles showed a higher total peak shift of $3.71 \mathrm{~nm}$, compared with $3.2-3.31 \mathrm{~nm}$ peak shifts for liposomes which deformed after adsorption $(>80 \mathrm{~nm})$. However, contrary to the discussed work, we observed a second stable diffusion-limited adsorption rate with high coverage, observed by a short plateau of the peak shift derivative (see Figure $2 \mathrm{~B}$ and its inset). This indicated two regions on the sensor where the second region has a lower rate of SUV adsorption by a factor of $0.50 \pm 0.01$. Such kinetics can be observed only after the higher adsorption kinetics region coverage is high enough that vesicle-vesicle interactions become appreciable. However, there is still a considerable portion of the second region available for diffusion-limited adsorption without vesicles influencing each other.

Interaction between Surfactants and the $\mathrm{SiO}_{2}$ Sensor. To clarify the effect of surfactants on the $\mathrm{SiO}_{2}$ sensor surface, the level of peak shift connected solely to the surfactants was first analyzed (further denoted as blank runs). The measure- ment followed the same setup as when coating the sensors with $\mathrm{SLB}$. However, the eggPC dispersion in $\mathrm{HEPES} / \mathrm{CaCl}_{2}$ was substituted with plain HEPES/ $\mathrm{CaCl}_{2}$ buffer. The blank results are shown as dotted lines in the figures corresponding to the particular surfactants (see Figure 2A-D). All of the surfactants adsorbed on the $\mathrm{SiO}_{2}$ surface to a low extent except for SDS.

The results of the three adsorbing surfactants show that unimeric surfactants increased the peak shift after the final water flush more than the corresponding micelles (Figure $2 \mathrm{~A}, \mathrm{C}, \mathrm{D}) . \mathrm{SiO}_{2}$ has a wide variety of groups exposed to a solution, and some of them are reported to be hydrophobic. ${ }^{22}$ Such groups can function as an anchor point for adsorption of hydrophobic tails of unimers, thus creating a sparse layer over the silica surface and enduring even a rinse with water. Moreover, with CHAPS and CTAB unimers, we observed a higher final peak shift of 1.10 and $0.89 \mathrm{~nm}$, respectively (Figure 2C,D). The zwitterionic/cationic head groups enable Coulombic interactions with the $\mathrm{SiO}_{2}$ surface. In contrast, lower peak shifts of 0.73 and $0.63 \mathrm{~nm}$ were observed for nonionic Triton X-100 unimers and micelles, respectively, which cannot use Coulombic forces for interactions (Figure 2A).

SDS was the only surfactant that decreased the NPS signal below the initial water reference by a peak shift of $0.32 \mathrm{~nm}$, regardless of whether SDS was in its micellar or unimeric form (when HEPES buffer containing $\mathrm{CaCl}_{2}$ was applied during blank runs) (see Figure 2B). This decrease was not observed 
when $\mathrm{HNO}_{3}$ was used in the pretreatment for immobilization of SVLs or when the HEPES buffer without calcium was used. The interactions between SDS and the sensor seem to follow a two-step mechanism. In the first step, the sodium cations are substituted by calcium from the buffer. When SDS is introduced, it has much higher electrostatic interaction with calcium ions than with sodium ions. ${ }^{23}$ Thus, calcium cations are effectively removed from the surface but the cation exchange is probably not efficient enough to saturate the surface with sodium ions. Overall, this effect results in a blue shift, similar to the one observed after rinsing the sensor with $2 \mathrm{M} \mathrm{HNO}_{3}$ (see Figure $3 \mathrm{~A}-\mathrm{D}$ ). This further strengthens our hypothesis about cation removal from the coating surface.

Interactions between Triton $\mathrm{X}-100$ and eggPC Membranes. Surfactant solubilization of lipid membranes depends on the surfactant flip-flop rate in the membrane and can be divided into two basic pathways, as described earlier. $^{24-26}$ According to this model, fast flipping surfactants first saturate both leaflets and pores are formed in the membrane. The final stage results in mixed surfactant-lipid micelles. Slow flipping surfactants, however, enrich only the one accessible leaflet and induce stress, resulting in a curvature and protrusion of the leaflet. Further, mixed surfactant-lipid micelles are formed, which can optionally fuse with the membrane, introducing surfactant molecules also to the inaccessible leaflet. The interaction studies of Triton X-100 with eggPC vesicles showed that the resulting solution contained both mixed vesicles and mixed micelles (mixed micelles appeared at 0.94 surfactant/lipid ratio). Both systems coexisted up to a ratio of 3.51 , after which mixed vesicles were fully solubilized. The addition of Triton X-100 was also reported to alter the liposome size, ${ }^{27}$ disrupt the membrane, ${ }^{28}$ and produce sheets composed of Triton X-100/phospholipid in contrast to the direct formation of mixed micelles by SDS. ${ }^{29}$

Interactions of Triton X-100 Unimers. Triton X-100 was analyzed at two concentrations $(0.1$ and $0.5 \mathrm{mM})$ below and above the CMC of $0.24 \mathrm{mM}$ (see Table 1). In contrast to all of

Table 1. Critical Micelle Concentrations of the Studied Surfactants in Water

\begin{tabular}{llcc}
\multicolumn{1}{c}{ surfactant } & $\begin{array}{l}\mathrm{CMC} \\
(\mathrm{mM})\end{array}$ & measurement method, temperature & reference \\
Triton X-100 & 0.24 & surface tension, $25{ }^{\circ} \mathrm{C}$ & 50 \\
SDS & 8.2 & surface tension, $25{ }^{\circ} \mathrm{C}$ & 50 \\
CHAPS & 6.67 & ultrafiltration, $22{ }^{\circ} \mathrm{C}$ & 51 \\
CTAB & 0.80 & surface tension, $25^{\circ} \mathrm{C}$ & 50 \\
\hline
\end{tabular}

the other surfactants, Triton X-100 showed slow dynamics of SLB saturation. This can be explained by the recently reported 500 times lower rate of flip-flop movements of Triton X-100 in SLB compared with SVL. ${ }^{30}$ The solution accessible leaflet becomes saturated very fast with surfactant, whereas the other leaflet gets slowly saturated by surfactant flip-flop, manifested by an immediate peak shift increase followed by a gradual peak shift rise over the course of $10 \mathrm{~min}$ (see Figure 2A). No similar gradual increase was observed when treating the SVL with Triton X-100. When Triton X-100 unimers were added to the SVL, there was just a negligible rise in the peak shift of $0.09 \mathrm{~nm}$ (see Figure 3A). This agrees with recent computer simulations, where an SLB was shown to be solubilized by a slow solubilization pathway, whereas vesicles were following a fast solubilization pathway $^{30}$ of a three-stage solubilization model. ${ }^{24-26,31}$

Interactions of Triton X-100 Micelles. Regarding the addition of Triton X-100 micelles (at $0.5 \mathrm{mM}$ concentration), opposite effects were observed with SLBs and SVLs. An increase in the peak shift was observed after adding the surfactant to SLBs, whereas a decrease in the peak shift occurred with SVLs. However, the resulting peak shift was almost the same ( 3.38 for SLB and 3.36 for SVL) relative to the water reference level of the bare sensor after $10 \mathrm{~min}$ of $0.5 \mathrm{mM}$ Triton X-100 rinse. This confirms that the solubilization process was different for the two systems but the resulting product was the same, corresponding most probably to bicelles or mixed micelles adsorbed on the $\mathrm{SiO}_{2}$ surface. We observed that the peak shift dropped almost immediately after the water rinse, leveling out at $1.25 \mathrm{~nm}$ from the original untreated sensor level with both SLBs and SVLs (see Figures 2A and 3A), which further confirms the observation. Also, a study by Armani et al. showed that mixed micelles were formed directly along with mixed DOPC-Triton X-100 SLBs when Triton X-100 micelles $(0.5 \mathrm{mM})$ interacted with DOPC SLB. ${ }^{29}$

CE Analysis. The CE experiments showed that both concentrations ( 0.1 and $0.5 \mathrm{mM}$ ) had a similar effect. For the SLB system, the change in the EOF mobility was 14.5 and $17.4 \%$ for 0.1 and $0.5 \mathrm{mM}$ Triton X-100 solutions, respectively, compared with the EOF mobility in a freshly SLB-coated capillary. In the case of SVL, the EOF change was slightly higher, amounting to 37.1 and $35.5 \%$ for 0.1 and $0.5 \mathrm{mM}$ Triton X-100, respectively. This clearly illustrates that not even a $0.5 \mathrm{mM}$ concentration of Triton $\mathrm{X}-100$ was able to completely remove the eggPC SLB from the fused silica surface. The effect of Triton X-100 on the EOF can be explained by a decrease of the overall net surface charge of the SLB, caused by incorporation of surfactants up to a specific eggPC/Triton X-100 saturation ratio. Saturation was reached in both cases due to the constant supply of fresh surfactant solution during $10 \mathrm{~min}$. This diminished the difference between the two concentrations. The developed surfactant/lipid capillary coating depended more on the physical state of the phospholipid membrane than on the applied concentration. The ratio of the resulting EOF of SLB versus SVL of 0.754 (eq 2) approaches the maximum packing fraction of 0.77 for a twodimensional arrangement of adsorbed vesicles, according to the random-loose-packed model. ${ }^{10,32}$ The decrease of EOF mobility upon moving from SLB to SVL is therefore connected to a lower total surface coverage of SVL compared with SLB.

$$
\mathrm{EOF}_{\text {ratio }}=\frac{\mathrm{EOF}_{\mathrm{SVL}}-\mathrm{EOF}_{\mathrm{SVL}, \text { surf }}}{\mathrm{EOF}_{\mathrm{SLB}}-\mathrm{EOF}_{\mathrm{SLB}, \text { surf }}}
$$

Here, $\mathrm{EOF}_{\mathrm{SVL}}$ and $\mathrm{EOF}_{\mathrm{SLB}}$ are the $\mathrm{EOF}$ mobilities after immobilizing SVL or SBL and $\mathrm{EOF}_{\mathrm{SVL} \text {,surf }}$ and $\mathrm{EOF}_{\mathrm{SLB} \text {, surf }}$ are the EOF mobilities after a subsequent rinse with the surfactant.

Interaction between SDS and eggPC Membranes. SDS along with Triton X-100 belongs to a group of surfactants that begin to solubilize the membranes structure after substantially disordering them. ${ }^{33}$ Formation of SDS-eggPC mixed micelles starts at an SDS/eggPC molar ratio of 3. It has been shown, that the size of the vesicles decreased until reaching a ratio of 2.4, after which the liposome size started to increase until liposomes were fully dissolved into micelles. ${ }^{34} \mathrm{~A}$ study by Kragh-Hansen et al. showed that it took up to $60 \mathrm{~min}$ to solubilize DOPC vesicles when the molar ratio of SDS/ 
Table 2. EOF Analysis of Interactions between Surfactants and eggPC SLBs or SVLs ${ }^{a}$

\begin{tabular}{|c|c|c|c|c|c|c|c|}
\hline surfactant & $\begin{array}{l}\text { concentration } \\
(\mathrm{mM})\end{array}$ & $\begin{array}{l}\text { adsorbed type of } \\
\text { membrane }\end{array}$ & $\begin{array}{c}\text { coated capillary EOF } \\
\left(10^{-8} \mathrm{~m}^{2} \mathrm{~V}^{-1} \mathrm{~s}^{-1}\right)\end{array}$ & $\begin{array}{l}\mathrm{RSD} \\
(\%)\end{array}$ & $\begin{array}{l}\text { EOF after surfactant rinse } \\
\left(10^{-8} \mathrm{~m}^{2} \mathrm{~V}^{-1} \mathrm{~s}^{-1}\right)\end{array}$ & $\begin{array}{l}\text { RSD } \\
(\%)\end{array}$ & $\begin{array}{l}\text { relative } \mathrm{EOF} \\
\text { change }(\%)\end{array}$ \\
\hline \multirow[t]{4}{*}{ Triton X-100 } & 0.1 & $\mathrm{SLB}\left(+5 \mathrm{mM} \mathrm{CaCl}_{2}\right)$ & 3.05 & 5.0 & 3.49 & 2.3 & 14.5 \\
\hline & 0.5 & $\mathrm{SLB}\left(+5 \mathrm{mM} \mathrm{CaCl}_{2}\right)$ & 2.76 & 7.2 & 3.23 & 3.9 & 17.4 \\
\hline & 0.1 & SVL $\left(2 \mathrm{M} \mathrm{HNO}_{3}\right)$ & 2.26 & 15.5 & 3.10 & 3.8 & 37.1 \\
\hline & 0.5 & SVL $\left(2 \mathrm{M} \mathrm{HNO}_{3}\right)$ & 2.41 & 9.2 & 3.27 & 3.7 & 35.5 \\
\hline \multirow[t]{4}{*}{ SDS } & 3.0 & $\operatorname{SLB}\left(+5 \mathrm{mM} \mathrm{CaCl}_{2}\right)$ & 2.89 & 2.2 & 2.92 & 5.0 & 1.1 \\
\hline & 16.0 & $\operatorname{SLB}\left(+5 \mathrm{mM} \mathrm{CaCl}_{2}\right)$ & 2.30 & 1.9 & 4.54 & 3.2 & 97.7 \\
\hline & 3.0 & $\operatorname{SVL}\left(2 \mathrm{M} \mathrm{HNO}_{3}\right)$ & 2.58 & 4.6 & 2.70 & 2.7 & 4.7 \\
\hline & 16.0 & SVL $\left(2 \mathrm{M} \mathrm{HNO}_{3}\right)$ & 2.43 & 6.1 & 4.64 & 3.6 & 91.3 \\
\hline \multirow[t]{4}{*}{ CHAPS } & 2.0 & $\operatorname{SLB}\left(+5 \mathrm{mM} \mathrm{CaCl}_{2}\right)$ & 2.91 & 3.9 & 3.02 & 3.6 & 3.5 \\
\hline & 16.0 & $\mathrm{SLB}\left(+5 \mathrm{mM} \mathrm{CaCl}_{2}\right)$ & 3.04 & 1.6 & 4.08 & 0.5 & 34.3 \\
\hline & 2.0 & SVL $\left(2 \mathrm{M} \mathrm{HNO}_{3}\right)$ & 2.24 & 10.2 & 3.00 & 3.7 & 34.1 \\
\hline & 16.0 & SVL $\left(2 \mathrm{M} \mathrm{HNO}_{3}\right)$ & 2.21 & 4.9 & 5.00 & 1.9 & 126.4 \\
\hline \multirow[t]{4}{*}{ СТАВ } & 0.5 & $\mathrm{SLB}\left(+5 \mathrm{mM} \mathrm{CaCl}_{2}\right)$ & 3.00 & 2.3 & $1.19^{c}$ & 15.0 & -60.3 \\
\hline & 2.0 & $\operatorname{SLB}\left(+5 \mathrm{mM} \mathrm{CaCl}_{2}\right)$ & 2.52 & 3.8 & $1.02^{c}$ & 15.0 & -59.8 \\
\hline & 0.5 & SVL $\left(2 \mathrm{M} \mathrm{HNO}_{3}\right)$ & 1.80 & 8.0 & $2.24^{b}$ & 16.6 & 24.3 \\
\hline & 2.0 & SVL $\left(2 \mathrm{M} \mathrm{HNO}_{3}\right)$ & 1.54 & 5.7 & 1.80 & 10.7 & 17.4 \\
\hline
\end{tabular}

$a_{n=5}$ ( 8 min electrophoretic analysis). ${ }^{b}$ Only three runs were measured when EOF marker was possible to detect within the standard 8 min measured time window. ${ }^{c}$ Only two runs were measured when EOF marker was possible to detect within the extended measurement window of 15 $\min$.

phospholipid was 21.8:1 (mass ratio of $8: 1$ ). ${ }^{24}$ The authors further suggested that SDS as a surfactant with a slow flip-flop movement in the membrane has to attack the bilayer only from the outer side by creating mixed surfactant/lipid bilayer leaflets, where phospholipids from vesicles are exchanged with the surfactant molecules. This was also supported by a lack of fusion of vesicles, typical for nonionic surfactants (e.g., Triton X-100) with high flip-flop movement. Slow flip-flop of SDS in 1-palmitoyl-2-oleoyl-sn-glycero-3-phosphocholine was also confirmed by isothermal titration calorimetry. ${ }^{35}$

Interaction of SDS Unimers. The anionic surfactant, SDS, did not stay on the surface either in unimeric or micellar form due to the negatively charged head group, as discussed above. SDS showed in both forms a negative drop of the peak shift of $0.32 \mathrm{~nm}$. Following the introduction of $3 \mathrm{mM}$ SDS to eggPC SLB, there was no change in the peak shift. After the water rinse, there was still a stable layer adsorbed on the surface, amounting to a peak shift of $1.85+0.32 \mathrm{~nm}$ (due to the SDS blank signal drop). The initial drop in the peak shift of $0.32 \mathrm{~nm}$ after adding SDS unimers to the SVL suggests that vesicles ruptured and planar structures are formed, resulting in a stable layer with a peak shift of $1.52 \mathrm{~nm}$ after the water rinse. The shape of the peak shift of the following water rinse confirms that very similar systems were formed. The NPS final signal of SVL-SDS system was $70.0 \%$ (i.e., $[1.52 \mathrm{~nm} /(1.85+0.32$ $\mathrm{nm})]$ ) of the SLB-SDS signal, which is near to the maximum packing ratio discussed above.

Interaction of SDS Micelles. SDS micelles are known to solubilize a lipid bilayer and form mixed micelles. ${ }^{34}$ However, it was recently reported that the complete solubilization is preceded by formation of elongated fibrils after introduction of $2 \mathrm{mM}$ SDS to an SLB formed by liposomes prepared by the solvent-assisted lipid bilayer method. ${ }^{36}$ This was evidenced by microscopic observation of SLB tagged with a fluorescent lipid. The fibrils started to appear $15 \mathrm{~s}$ after the beginning of a $2 \mathrm{mM}$ SDS rinse, and the elongation continued with some fibrils reaching up to $20 \mu \mathrm{m}$. This superstructure was, however, solubilized together with the underlying SLB by a continuous surfactant rinse, and after $10 \mathrm{~min}$, there was no residual fluorescence detected on the investigated surface. Such superstructure formulation would be manifested in NPS by a decrease in the peak shift, as part of the phospholipid would be incorporated in the fibrils. A short decay length of the evanescent wave will prevent fibrils from being efficiently detected. This effect was confirmed by our NPS measurements. When the chamber with SLB was rinsed with a $16 \mathrm{mM}$ SDS solution, a $0.78 \mathrm{~nm}$ drop in the peak shift was observed. A succeeding water rinse removed the resulting SDS-SLB bicelles from the surface, resulting in a peak shift of $0.32 \mathrm{~nm}$, as compared with the water reference level of the bare sensor. This mechanism seems to be probable, especially comparing with the data obtained for the interaction study between SDS micelles and the SVL (see Figure 3B). Fibrils cannot be formed from SUVs, and with NPS, there was an immediate drop in the peak shift of $3.12 \mathrm{~nm}$ after adding SDS micelles. This means that most of the lipid vesicles were removed from the $\mathrm{SiO}_{2}$ surface already with SDS micelles, producing the final residual peak shift of $0.10 \mathrm{~nm}$ compared to that of the bare sensor.

CE Analysis. Using CE capillaries coated with SLBs or SVLs showed that $3 \mathrm{mM}$ SDS changed the EOF mobility only slightly by 1.1 and $4.7 \%$ for the respective systems. This is rather surprising, considering that SDS incorporation will change the net surface charge to negative value, and therefore the EOF should increase. The observed EOF, however, confirms that a similar system is obtained regardless of the membrane (SLB or SVL); thus, a similar surface net charge of adsorbed bicelles was observed. Sixteen millimolar SDS resulted in a substantial change of the EOF mobility; 97.7 and $91.3 \%$ for SLB and SVL, respectively (see Table 2 for absolute values and SDs). The CE analysis further supports our hypothesis that there is still a residual SDS-eggPC layer on the silica surface, as it was not possible to fully restore the EOF mobility; the value was only $67.5 \%$ of the original EOF mobility in the uncoated capillary.

Interaction between CHAPS and eggPC Membranes. CHAPS is widely used for solubilizing membranes and membrane proteins. The solubilization process follows the three-stage model described above. The first stage includes saturation of the bilayer with CHAPS, followed by a second 
stage including formation of mixed micelles of surfactants and phospholipids. In the final stage, phospholipids are fully dissolved into micelles, amounting roughly to $12 \mathrm{~nm}$ in hydrodynamic diameter. ${ }^{37}$ The molar ratios corresponding to the breakpoints of the first/second and second/third solubilization phase are 0.4 and 1.04 CHAPS/phospholipid molar ratio, respectively. ${ }^{37}$ Viriyaroj et al. showed that CHAPS interacts with eggPC large unilamellar vesicles in four stages. ${ }^{38}$ The first stage is distribution of CHAPS into the membrane without disrupting the structure of the membrane, followed by a second stage of forming uneven small surfactant-rich vesicles. In the third stage, rodlike micelles in mixture with vesicles are created, and in the final stage total solubilization into spherical micelles occurs. The respective molar effective ratios of CHAPS in eggPC membrane were 0.04, 0.21, and 0.52.

Interactions of CHAPS Unimers with SLBs. On the basis of the work of Cladera et al., ${ }^{37}$ three phases of CHAPSphospholipid interactions were determined. The breakpoints corresponded to molar ratios of 0.4 and 1.04 between phase I/ II (complete saturation of liposomes) and phase II/III (complete solubilization of liposomes), respectively. However, the molar partition is not easily determined in a fluidic setup for supported membrane systems and it is changing over time due to rinsing with fresh surfactant medium until reaching a saturation point. The concentration of $2 \mathrm{mM}$ CHAPS showed considerable adsorption to the bare silica surface with a linear increase during the surfactant rinse, reaching a maximum peak shift of $2.55 \mathrm{~nm}$ (see Figure 2C blank). No such increase was observed during interaction with the SLB, where a constant peak shift was maintained after the initial increase. On the basis of the phases of the interaction mentioned above, one might expect to be in phase I where the SLB is enriched with CHAPS. Incorporation of CHAPS to the sensing region resulted in an increase of the RI and in a subsequent increase of the peak shift (see Figure 2C). Nevertheless, the following water rinse of the system showed that the SLB was at least partly solubilized; the peak shift was gradually decreasing from its original value of $2.81 \mathrm{~nm}$ in water, as part of the adsorbed material was rinsed off the surface, and it was stabilized after $40 \mathrm{~min}$ at a value of 1.59 $\mathrm{nm}$ (see Figure 2C). The peak shift was reduced by a factor of 1.77. This suggests that the interacting system was actually in phase II and that the solubilization process was already proceeding. The long equilibration time of the peak shift suggests that the mixed micelles were forming over a long time span. The system was approaching the form of an adsorbed layer of pure CHAPS unimers on silica (peak shift of $1.10 \mathrm{~nm}$ ).

Interactions of CHAPS Micelles with SLBs. Application of micelles of CHAPS (concentration $16 \mathrm{mM}$ ) to the SLB resulted in a fast exchange of molecules on the sensor surface, characterized by a sharp peak, after which the peak shift returned to almost the reference value on a bare sensor during the subsequent water rinse. This was well expected as CHAPS is regularly used for cleaning of various sensing surfaces in biomembrane science. ${ }^{39,40}$ Therefore, the system was in phase III where complete solubilization of phospholipids occurred, producing a clean silica surface.

Interactions of CHAPS with SVLs. The peak shift change of the interaction between CHAPS and SVL followed a pattern very similar to that observed for CHAPS-SLB with both concentrations of the surfactant. The SVL peak shift of $4.35 \mathrm{~nm}$ increased by $0.68 \mathrm{~nm}$ when the SVL surface was rinsed with 2 $\mathrm{mM}$ CHAPS, but it dropped to a value of $3.01 \mathrm{~nm}$ after the water rinse (see Figure 3C). The final peak shift was lowered by a factor of 1.45 , which is lower than that obtained using the SLB (1.77; cf. section above). This finding suggests another process competing with solubilization, which could be related to a structural change of the liposomes. Most probably, the unimers induced higher stress and flexibility, followed by spreading/relaxation of the bilayer/surfactant system and higher coverage of the sensing surface. Considering the maximum packing fraction for vesicles of 0.77 , there was $23 \%$ of unoccupied space on the surface. Following the effect of CHAPS on SLB (a decrease of 1.77) and applying it on the SVL, the final peak shift change would give a value of $2.45 \mathrm{~nm}$. Considering a $77 \%$ coverage in the case of the SVL, the increase to the full coverage would give a peak shift of $3.18 \mathrm{~nm}$. Finally, dividing the measured peak shift of $3.01 \mathrm{~nm}$ by the ideal value for full coverage $(3.18 \mathrm{~nm})$ increases the coverage to $94.65 \%$. On the basis of this calculation, it can be speculated that CHAPS did not break the vesicles but rather induced abnormalities in the vesicle structure, resulting in higher surface coverage. When CHAPS in its micellar form was applied to the SVL, we observed complete removal from the silica surface, as in the case of the SLB.

CE Analysis. On the basis of the CE experiments, the net charge of the capillary surface coated with SLB remained unchanged at $2 \mathrm{mM}$ concentration of CHAPS, whereas the net charge decreased after rinsing with $16 \mathrm{mM}$ CHAPS. The corresponding changes in the EOF mobility, as compared to the values before adding the surfactant, were 3.5 and $34.3 \%$ for $2 \mathrm{mM}$ and $16 \mathrm{mM}$ CHAPS, respectively (see Table 1). It should be noted that due to the zwitterionic character of CHAPS, its incorporation will not change the overall net charge of the lipid membrane and therefore the increase in the EOF mobility is directly related to the removal of lipids from the silica capillary wall. However, the increase in the EOF mobility was dramatic when the SVL coating was analyzed; the EOF mobility increased by 34.1 and $126.4 \%$ using 2 and $16 \mathrm{mM}$ CHAPS, respectively. This is in contradiction with the NPS results, which suggests that the removal was similar regardless of the membrane system, i.e., the SLB or SVL.

In the CHAPS-SLB system, calcium cations probably were the reason for the observed difference. It has been shown that metal cations have an important effect on improving the stability of phospholipid coatings in fused silica capillaries by changing the density of the coating. ${ }^{41,42}$ This effect was observed with negatively charged and zwitterionic phospholipids. Similarly, CHAPS due to its zwitterionic nature probably interchanged with phospholipids when unimers were in the rinsing solution, thus maintaining the layer screening off the silanol groups on fused silica capillary. Calcium serves here as a linking agent helping to keep CHAPS on the surface. Adsorbed surfactant molecules will create a double layer and screen off the charge of the silanol groups, responsible for the EOF mobility. This process is regularly used in preparation of multilayer coatings in capillary electrophoresis for manipulation of the EOF and hindering analyte interactions with the capillary wall. $^{43}$ NPS analysis showed that a semistable layer was developed upon rinsing with CHAPS unimers but this was not observed in the case of micelles. However, there was a residual peak shift after the CHAPS rinse in the blank NPS analysis. Taken together, it seems that first, the SLB was fully solubilized but a semidynamic coating developed on the capillary surface upon a prolonged rinse with CHAPS micelles due to the presence of $\mathrm{Ca}^{2+}$. When the $\mathrm{Ca}^{2+}$ ions were left out, the SVL 
was very efficiently removed with CHAPS micelles, resulting in a practically clean $\mathrm{SiO}_{2}$ capillary surface.

Interaction between CTAB and eggPC Membranes. $\mathrm{CTAB}$ has been regularly used as a disinfecting agent, and its main function is disruption of bacterial cell membranes. ${ }^{44,45}$ In contrast to Triton X-100 and SDS, CTAB has been shown to increase the vesicle microviscosity with increasing molar concentration, suggesting a tighter packing of the mixed system. ${ }^{46}$ However, differential scanning calorimetry study of CTAB using 1,2-dipalmitoyl-sn-glycero-3-phosphocholine (DPPC) vesicles indicated that CTAB destabilizes a gel state of the bilayer by making it more fluid. Lima et al. concluded that on a general level, CTAB induced destabilization of the DPPC bilayer. ${ }^{47}$ This was further proven in the study of Kuldvee et al., who analyzed eggPC coatings on fused silica capillary. ${ }^{16}$ The addition of CTAB during the coating step did not improve the overall coating stability, even though the positively charged surface was supposed to improve electrostatic interactions between the bilayer and the negatively charged vicinal silanols. However, the coating stability was enhanced when $\mathrm{CaCl}_{2}$ along with $\mathrm{CTAB}$ was added to the coating solution. ${ }^{16}$ Also, two different domains of SLB were observed when the CTAB molar content in DPPC bilayer was increased above $10 \%$. The $\mathrm{CTAB}$ and $\mathrm{DPPC}$ rich regions were shown to have a thickness of $3 \mathrm{~nm}$ (CTAB bilayer height ${ }^{48}$ ) and $5 \mathrm{~nm}$, respectively. ${ }^{47}$

Interactions of CTAB with SLBs. Because of the slightly negatively charged eggPC membrane, ${ }^{1} \mathrm{CTAB}$ with a positive net charge is able to electrostatically interact with the membrane surface. When $\mathrm{CTAB}$ unimers were applied to the SLB, the peak shift increased by $3.52 \mathrm{~nm}$ from the original SLB level (see Figure 2D). At first the rise of $2.5 \mathrm{~nm}$ in the peak shift was immediate, whereas it took 10 more min to add another $1 \mathrm{~nm}$ with the slope progressively decreasing. The peak shift dropped immediately after rinsing the SLB with water, and the peak shift continued to exponentially decrease for the next $40 \mathrm{~min}$. The total drop was $2.33 \mathrm{~nm}$, leaving the peak shift still at a value $4.81 \mathrm{~nm}$ higher than the level of the water reference for the sensor and at a value $1.12 \mathrm{~nm}$ higher than that of the SLB in water. When the SLB was rinsed with the micellar solution (i.e., $2.0 \mathrm{mM} \mathrm{CTAB}$ ), a sharp increase of the peak shift was closely followed by a small drop, which continued as a flat line with a $0.91 \mathrm{~nm}$ difference from the SLB peak shift level. Rinsing with water caused a decrease in the peak shift with the slope decreasing gradually over $50 \mathrm{~min}$, with a final peak shift difference of $1.71 \mathrm{~nm}$ from the bare sensor level.

Interactions of CTAB with SVLs. Interaction of the SVL with $\mathrm{CTAB}$ resulted in a similar peak shift change (Figure 3D). Application of unimers to the SVL caused a gradually slowing increase in the peak shift, stabilizing within $7 \mathrm{~min}$ at a peak shift of $0.92 \mathrm{~nm}$ higher than the SLB level. The subsequent water rinse produced a decrease in the peak shift, and the maximum slope of the drop was comparable to that of the SLB/CHAPS system (1.722 and $1.639 \mathrm{~nm}$ for the SLB/CHAPS and the SVL/CHAPS, respectively). The final peak shift change amounted to $2.29 \mathrm{~nm}$ compared with the water reference level of the bare sensor. Adding a micellar CTAB solution to the SVL resulted in exactly the same pattern as that with the SLB (Figure 2D). During the CTAB rinsing, the peak shift increased by $0.41 \mathrm{~nm}$ from the SVL level in water. A subsequent water rinse decreased the peak shift to $1.59 \mathrm{~nm}$ from the bare sensor water reference level. It should be noted that CTAB produced a very high peak shift in the blank NPS measurements (Figure 2D). The $0.5 \mathrm{mM}$ CTAB (unimers) blank showed a difference in the peak shift of $2.34 \mathrm{~nm}$, whereas the $2.0 \mathrm{mM}$ CTAB (micelles) blank increased the peak shift to $3.32 \mathrm{~nm}$, compared with the water reference level. A subsequent water rinse showed residues of surfactant molecules adsorbed on the surface. This was confirmed by peak shift differences of 0.89 and $0.41 \mathrm{~nm}$ from the bare sensor water reference level for the respective concentrations.

Formation of Bilayer from CTAB Unimers. The observed increase in the peak shift of the SLB/CTAB unimer system (3.52 $\mathrm{nm}$ above the SLB peak shift) is more than the total change in the $\mathrm{CTAB}$ peak shift observed in the blank measurements $(2.34 \mathrm{~nm})$, see Figure $2 \mathrm{D}$. This is a unique behavior compared with the other analyzed surfactants. However, the same was not observed with the SVL/CTAB unimer system. It has been shown that $\mathrm{CTAB}$ can form bilayers on negatively charged surfaces with a thickness of $3.2 \pm 0.2$ $\mathrm{nm} .{ }^{48}$ This could partly explain the observed drastic increase in the peak shift of the SLB/CTAB unimer system. For this particular case, the SLB produced a $3.55 \mathrm{~nm}$ peak shift (approximately a $5 \mathrm{~nm}$ thick layer) and simple extrapolation to the $2.34 \mathrm{~nm}$ peak shift of the blank CTAB leads to a $3.34 \mathrm{~nm}$ thick layer of CTAB. This is good agreement with the literature value. $^{48}$ The blank measurements of the micellar solution (2 $\mathrm{mM}$ CTAB) showed a peak shift almost equal to that of SLB (3.24 $\mathrm{nm}$ compared to $3.50 \mathrm{~nm}$ ). This speaks for a denser or more swollen CTAB layer or even whole micelles. However, this structure was less stable against water. Combining the observations on CTAB unimer interactions with SLBs and SVLs leads us to suggest that the CTAB bilayer was built up on top of the SLB.

Incorporation of CTAB into the Bilayer. The second effect is most probably related to the incorporation of $C T A B$ unimers into the outer leaflet of the membrane, with subsequent flipping into the inner leaflet facing the sensor coating. It has been shown that alkyltrimethylammonium bromides translocate to the inner leaflet in the course of tens of minutes. ${ }^{49}$ We observed a slow increase in the peak shift after an immediate jump of 2.5 $\mathrm{nm}$ due to fast CTAB bilayer formation on the SLB. A subsequent water rinse removed the $C T A B$ bilayer from the SLB (2.33 nm peak shift drop compared to $2.34 \mathrm{~nm}$ of the CTAB unimer blank measurement) but preserved the SLB enriched with CTAB.

In the case of adding CTAB unimers to the SVL, the increase in the peak shift was small (0.92 nm from the SVL level). Because part of the liposome bilayer was outside the sensing region of NPS, ${ }^{9}$ the CTAB bilayer attached on the outer leaflet of the vesicles could not be detected. A subsequent water rinse showed that CTAB unimers destabilized the structure of the vesicles, evidenced by a decrease in the peak shift of $3.01 \mathrm{~nm}$. The similar maximum slope of the drop for SLB and SVL suggests that the effect of rinsing with water was similar for both systems (i.e., removal of the CTAB bilayer). The final peak shift amounted to $52.3 \%$ of the original SVL, which strongly supports the idea of vesicle adsorption destabilization.

A higher concentration of CTAB (micelles) interacted similarly with both adsorbed systems, as seen by a sharp spike, followed by a flat line in NPS (see Figures 2D and 3D). However, this interaction differed much from that observed for CTAB unimers. Also the final peak shift differed slightly after the water rinse (1.71 vs $1.59 \mathrm{~nm}$ for SLB and SVL, respectively). The most probable reason is fast solubilization of the lipid membrane (seen as a small spike in the beginning of 
the rinse), followed by an immediate attachment of newly formed mixed micelles to the sensor surface. As no adsorption of $\mathrm{CTAB}$ micelles was observed in the blank measurements, enrichment of CTAB micelles with phospholipids (eggPC) seems to be critical for the adsorption.

CE Analysis. The introduction of CTAB to the SLB on the CE capillary surface showed a 60.3 and $59.8 \%$ decrease in the EOF mobility using 0.5 and $2.0 \mathrm{mM} \mathrm{CTAB}$, respectively (Table 2). In contrast, when the CE capillary was coated with intact SVLs, the EOF mobility increased by 24.3 and $17.4 \%$ using 0.5 and $2.0 \mathrm{mM} \mathrm{CTAB}$, respectively (Table 2). However, the net surface charge of the $\mathrm{CTAB} /$ lipid coating was further developing at subsequent analyses, as seen in migration time RSDs, to $10.6-16.6 \%$ due to unstable prolonged migration times of the EOF marker (see Table 2).

The CE results are in good agreement with the NPS data, suggesting the incorporation of CTAB into the SLB. The shielded charge of the dissociated silanol groups by the SLB or the SVL itself was further diminished when the net charge of the lipid membrane changed to positive due to CTAB incorporation. However, the system was highly unstable and the EOF mobility marker was detected only twice out of five runs due to a very low EOF; the peak of the EOF mobility marker was not migrating within 15 min during the first three runs. This actually means that over the increasing number of analysis, the charges of the dissociated silanols were screened off more efficiently; therefore, the mixed system was spread more evenly on the inner capillary surface. The EOF was similar regardless of the concentration of $\mathrm{CTAB}$, confirming that unimers were able to overlay the silica surface as effectively as micelles. However, there was a considerable difference in the EOF mobility of capillaries coated with SLBs or SVLs. This could be explained by the work of Kuldvee et al. ${ }^{16}$ where micrometer concentrations of $\mathrm{CTAB}$ premixed with $\mathrm{CaCl}_{2}$ and eggPC were shown to improve the stability of the coating. However, it has to be noted that in our study, the used concentrations of $\mathrm{CTAB}$ were more than hundred times higher.

\section{CONCLUSIONS}

A fast liposome immobilization method for formation of supported membrane coatings on $\mathrm{SiO}_{2}$-coated sensors was developed. The coating was done in 5 and $10 \mathrm{~min}$ for SLB and SVL, respectively, using $30 \mathrm{~nm}$ sonicated eggPC vesicles. This approach saves a considerable amount of phospholipids, which is of great importance for systems with limited amounts of lipids and also increases the throughput of the utilized NPS method. A set of four surfactants was analyzed with the adsorbed biomembranes. The nonionic surfactant Triton X-100 showed similar NPS results for every concentration regardless of the supported membrane state (SLB and SVL). The CE analysis of Triton X-100 correlated very well with the theoretical surface coverage of SLB and SVL, regardless of the concentration. SDS micelles proved to be a strong membrane solubilization agent for both studied membrane systems. In contrast, SDS unimers were incorporated into the lipid bilayer and formed a stable bicellar system adsorbed on the $\mathrm{SiO}_{2}$ surface. This was also confirmed by $\mathrm{CE}$ analysis. Similarly to SDS, CHAPS at a concentration above its CMC was able to remove adsorbed SLBs and intact vesicles from the sensor's surface. In contrast to NPS, CE analyses showed a considerable change in the membrane charge in the case of CHAPS-SVL interactions. Here, the calcium ions seem to make a difference by supporting a semipermanent layer of
CHAPS, which screened off the dissociated silanol groups. However, CHAPS unimers interacted quite differently with the liposomes; CHAPS unimers produced a stable layer of bicelles with the SLB, whereas structural abnormalities were induced in vesicles of SVL. NPS analysis of CTAB unimers suggested a buildup of a CTAB bilayer on top of the SLB, which was removed by a water rinse. However, the SLB enriched with $\mathrm{CTAB}$ undertook long relaxation of the layer at both concentrations. NPS analysis of the interaction between CTAB unimers and SVL showed similar long relaxation times but the CTAB top layer was not detected, most probably due to the short sensing depth. The long equilibration time along with the importance of calcium as a stabilizing agent of the supported $\mathrm{CTAB} /$ eggPC systems were the major findings from the CE analysis. The obtained results confirm that NPS can provide valuable data about mechanistic interactions of membranes and amphiphilic compounds, whereas CE is a welcomed complementary methodology for either supporting or disapproving suggested mechanisms. Moreover, the usage of two different types of supported membranes, i.e., SLB and SVL, strongly aided the interpretation of the analysis data and understanding of the interaction mechanisms.

\section{ASSOCIATED CONTENT}

\section{S Supporting Information}

The Supporting Information is available free of charge on the ACS Publications website at DOI: 10.1021/acs.langmuir.8b01074.

Structures of the used surfactants (S1); change in LSPR peak shift as a function of increasing refractive index of ethylene glycol/water solutions (S2) (PDF)

\section{AUTHOR INFORMATION}

\section{Corresponding Authors}

*E-mail: dusa@iach.cz. Phone +420532290217 (F.D.).

*E-mail: susanne.wiedmer@helsinki.fi. Phone +358294150183 (S.K.W.).

ORCID $\odot$

Joanna Witos: 0000-0003-0021-1599

Susanne K. Wiedmer: 0000-0002-3097-6165

\section{Notes}

The authors declare no competing financial interest.

\section{ACKNOWLEDGMENTS}

This work was supported by the Programme for research and mobility support of starting researchers of the Czech Academy of Sciences number MSM200311602 (F.D.) and by institutional support RVO:68081715 (F.D.). Financial support from the Academy of Finland (grant number 266342) is acknowledged (S.K.W.).

\section{ABBREVIATIONS:}

$\mathrm{CE}$, capillary electrophoresis; $\mathrm{CTAB}$, cetyltrimethylammonium bromide; CHAPS, 3-[(3-cholamidopropyl)dimethylammonio]1-propanesulfonate; CMC, critical micelle concentration; DOPC, 1,2-dioleoyl-sn-glycero-3-phosphocholine; DPPC, 1,2dipalmitoyl-sn-glycero-3-phosphocholine; eggPC, egg phosphatidylcholine; EOF, electroosmotic flow; LSPR, localized surface plasmon resonance; NPS, nanoplasmonic sensing; SUV, small unilamellar vesicles; SDS, sodium dodecyl sulfate; SLB, supported lipid bilayer; SVL, supported vesicle layer; Triton 
X-100, 4-(1,1,3,3-tetramethylbutyl)phenyl-poly(ethylene glycol)

\section{REFERENCES}

(1) Marcelino, J.; Lima, J. L. F. C.; Reis, S.; Matos, C. Assessing the Effects of Surfactants on the Physical Properties of Liposome Membranes. Chem. Phys. Lipids 2007, 146, 94-103.

(2) Keller, C. A.; Glasmästar, K.; Zhdanov, V. P.; Kasemo, B. Formation of Supported Membranes from Vesicles. Phys. Rev. Lett. 2000, 84, 5443-5446.

(3) Cho, N. J.; Jackman, J. A.; Liu, M.; Frank, C. W. PH-Driven Assembly of Various Supported Lipid Platforms: A Comparative Study on Silicon Oxide and Titanium Oxide. Langmuir 2011, 27, 37393748.

(4) Langhammer, C.; Larsson, E. M.; Kasemo, B.; Zorić, I. Indirect Nanoplasmonic Sensing: Ultrasensitive Experimental Platform for Nanomaterials Science and Optical Nanocalorimetry. Nano Lett. 2010, 10, 3529-3538.

(5) Larsson, E. M.; Syrenova, S.; Langhammer, C. Nanoplasmonic Sensing for Nanomaterials Science. Nanophotonics 2012, 1, 249-266. (6) Jackman, J. A.; Špačková, B.; Linardy, E.; Kim, M. C.; Yoon, B. K.; Homola, J.; Cho, N.-J. Nanoplasmonic Ruler to Measure Lipid Vesicle Deformation. Chem. Commun. 2016, 52, 76-79.

(7) Jonsson, M. P.; Jönsson, P.; Dahlin, A. B.; Höök, F. Supported Lipid Bilayer Formation and Lipid-Membrane-Mediated Biorecognition Reactions Studied with a New Nanoplasmonic Sensor Template. Nano Lett. 2007, 7, 3462-3468.

(8) Jackman, J. A.; Rahim Ferhan, A.; Cho, N.-J. Nanoplasmonic Sensors for Biointerfacial Science. Chem. Soc. Rev. 2017, 46, 36153660.

(9) Zan, G. H.; Jackman, J. A.; Kim, S. O.; Cho, N. J. Controlling Lipid Membrane Architecture for Tunable Nanoplasmonic Biosensing. Small 2014, 10, 4828-4832.

(10) Jackman, J. A.; Zhdanov, V. P.; Cho, N. J. Nanoplasmonic Biosensing for Soft Matter Adsorption: Kinetics of Lipid Vesicle Attachment and Shape Deformation. Langmuir 2014, 30, 9494-9503.

(11) Duša, F.; Witos, J.; Karjalainen, E.; Viitala, T.; Tenhu, H.; Wiedmer, S. K. Novel Cationic Polyelectrolyte Coatings for Capillary Electrophoresis. Electrophoresis 2016, 37, 363-371.

(12) Witos, J.; Samuelsson, J.; Cilpa-Karhu, G.; Metso, J.; Jauhiainen, M.; Riekkola, M.-L. Partial Filling Affinity Capillary Electrophoresis Including Adsorption Energy Distribution Calculations-towards Reliable and Feasible Biomolecular Interaction Studies. Analyst 2015, 140, 3175-3182.

(13) Ruokonen, S.-K.; Duša, F.; Lokajová, J.; Kilpeläinen, I.; King, A. W. T.; Wiedmer, S. K. Effect of Ionic Liquids on the Interaction between Liposomes and Common Wastewater Pollutants Investigated by Capillary Electrophoresis. J. Chromatogr. A 2015, 1405, 178-187.

(14) Jackman, J. A.; Avsar, S. Y.; Ferhan, A. R.; Li, D.; Park, J. H.; Zhdanov, V. P.; Cho, N.-J. J.; Yorulmaz Avsar, S.; Ferhan, A. R.; Li, D.; et al. Quantitative Profiling of Nanoscale Liposome Deformation by a Localized Surface Plasmon Resonance Sensor. Anal. Chem. 2017, 89, $1102-1109$

(15) Gaš, B.; Jaroš, M.; Hruska, V.; Zusková, I.; Stedry, M. PeakMaster - A Freeware Simulator of Capillary Zone Electrophoresis. LC.GC Eur. 2005, 18, 282-288.

(16) Kuldvee, R.; Lindén, M. V.; Wiedmer, S. K.; Riekkola, M.-L. Influence of Cetyltrimethylammonium Bromide on Phosphatidylcholine-Coated Capillaries. Anal. Bioanal. Chem. 2004, 380, 293-302.

(17) Witos, J.; Russo, G.; Ruokonen, S.-K.; Wiedmer, S. K. Unraveling Interactions between Ionic Liquids and Phospholipid Vesicles Using Nanoplasmonic Sensing. Langmuir 2017, 33, 10661076.

(18) Dacic, M.; Jackman, J. A.; Yorulmaz, S.; Zhdanov, V. P.; Kasemo, B.; Cho, N.-J. Influence of Divalent Cations on Deformation and Rupture of Adsorbed Lipid Vesicles. Langmuir 2016, 32, 64866495.

(19) Reimhult, E.; Höök, F.; Kasemo, B. Intact Vesicle Adsorption and Supported Biomembrane Formation from Vesicles in Solution:
Influence of Surface Chemistry, Vesicle Size, Temperature, and Osmotic Pressure †. Langmuir 2003, 19, 1681-1691.

(20) Reimhult, E.; Zäch, M.; Höök, F.; Kasemo, B. A Multitechnique Study of Liposome Adsorption on Au and Lipid Bilayer Formation on SiO2. Langmuir 2006, 22, 3313-3319.

(21) Hautala, J. T.; Wiedmer, S. K.; Riekkola, M.-L. Anionic Liposomes in Capillary Electrophoresis: Effect of Calcium on 1Palmitoyl-2-Oleyl- Sn-Glycero-3-Phosphatidylcholine / Phosphatidylserine-Coating in Silica Capillaries. Anal. Bioanal. Chem. 2004, 378, 1769-1776.

(22) Stutz, H. Protein Attachment onto Silica Surfaces - A Survey of Molecular Fundamentals, Resulting Effects and Novel Preventive Strategies in CE. Electrophoresis 2009, 30, 2032-2061.

(23) Iyota, H.; Tomimitsu, T.; Aratono, M. Miscibility of Calcium Chloride and Sodium Dodecyl Sulfate in the Adsorbed Film and Aggregates. Colloid Polym. Sci. 2010, 288, 1313-1320.

(24) Kragh-Hansen, U.; le Maire, M.; Møller, J. V. The Mechanism of Detergent Solubilization of Liposomes and Protein-Containing Membranes. Biophys. J. 1998, 75, 2932-2946.

(25) Lichtenberg, D.; Ahyayauch, H.; Goñi, F. M. The Mechanism of Detergent Solubilization of Lipid Bilayers. Biophys. J. 2013, 105, 289299.

(26) Lichtenberg, D.; Ahyayauch, H.; Alonso, A.; Goñi, F. M. Detergent Solubilization of Lipid Bilayers: A Balance of Driving Forces. Trends Biochem. Sci. 2013, 38, 85-93.

(27) López, O.; De La Maza, A.; Coderch, L.; López-Iglesias, C.; Wehrli, E.; Parra, J. L. Direct Formation of Mixed Micelles in the Solubilization of Phospholipid Liposomes by Triton X-100. FEBS Lett. 1998, 426, 314-318.

(28) De la Maza, a; Parra, J. L. Vesicle-Micelle Structural Transition of Phosphatidylcholine Bilayers and Triton X-100. Biochem. J. 1994, 303, 907-914.

(29) Sun, V.; Armani, A. M. Real-Time Detection of Lipid Bilayer Assembly and Detergent-Initiated Solubilization Using Optical Cavities. Appl. Phys. Lett. 2015, 106, No. 071103.

(30) Pizzirusso, A.; De Nicola, A.; Sevink, G. J. A.; Correa, A.; Cascella, M.; Kawakatsu, T.; Rocco, M.; Zhao, Y.; Celino, M.; Milano, G. Biomembrane Solubilization Mechanism by Triton X-100: A Computational Study of the Three Stage Model. Phys. Chem. Chem. Phys. 2017, 19, 29780-29794.

(31) Stuart, M. C. A.; Boekema, E. J. Two Distinct Mechanisms of Vesicle-to-Micelle and Micelle-to-Vesicle Transition Are Mediated by the Packing Parameter of Phospholipid-Detergent Systems. Biochim. Biophys. Acta, Biomembr. 2007, 1768, 2681-2689.

(32) Hinrichsen, E. L.; Feder, J.; Jøssang, T. Random Packing of Disks in Two Dimensions. Phys. Rev. A 1990, 41, 4199-4209.

(33) Nazari, M.; Kurdi, M.; Heerklotz, H. Classifying Surfactants with Respect to Their Effect on Lipid Membrane Order. Biophys. J. 2012, 102, 498-506.

(34) López, O.; Cócera, M.; Wehrli, E.; Parra, J. L.; de la Maza, A. Solubilization of Liposomes by Sodium Dodecyl Sulfate: New Mechanism Based on the Direct Formation of Mixed Micelles. Arch. Biochem. Biophys. 1999, 367, 153-160.

(35) Keller, S.; Heerklotz, H.; Blume, A. Monitoring Lipid Membrane Translocation of Sodium Dodecyl Sulfate by Isothermal Titration Calorimetry. J. Am. Chem. Soc. 2006, 128, 1279-1286.

(36) Yoon, B. K.; Jackman, J. A.; Kim, M. C.; Cho, N.-J. J. Spectrum of Membrane Morphological Responses to Antibacterial Fatty Acids and Related Surfactants. Langmuir 2015, 31, 10223-10232.

(37) Cladera, J.; Rigaud, J. L.; Villaverde, J.; Duñach, M. Liposome Solubilization and Membrane Protein Reconstitution Using Chaps and Chapso. Eur. J. Biochem. 1997, 243, 798-804.

(38) Viriyaroj, A.; Kashiwagi, H.; Ueno, M. Process of Destruction of Large Unilamellar Vesicles by a Zwitterionic Detergent, CHAPS: Partition Behavior between Membrane and Water Phases. Chem. Pharm. Bull. 2005, 53, 1140-1146.

(39) Lee, T. H.; Hall, K. N.; Swann, M. J.; Popplewell, J. F.; Unabia, S.; Park, Y.; Hahm, K. S.; Aguilar, M. I. The Membrane Insertion of Helical Antimicrobial Peptides from the N-Terminus of Helicobacter 
Pylori Ribosomal Protein L1. Biochim. Biophys. Acta, Biomembr. 2010,

1798, 544-557.

(40) Granqvist, N.; Yliperttula, M.; Välimäki, S.; Pulkkinen, P.; Tenhu, H.; Viitala, T. Control of the Morphology of Lipid Layers by Substrate Surface Chemistry. Langmuir 2014, 30, 2799-2809.

(41) Wells, S. S.; De La Toba, E.; Harrison, C. R. Metal Cation Control of Electroosmotic Flow Magnitude in Phospholipid-Coated Capillaries. Electrophoresis 2016, 37, 1303-1309.

(42) Lindén, M. V.; Wiedmer, S. K.; Hakala, R. M. S.; Riekkola, M. L. Stabilization of Phosphatidylcholine Coatings in Capillary Electrophoresis by Increase in Membrane Rigidity. J. Chromatogr. A 2004, 1051, 61-68.

(43) Katayama, H.; Ishihama, Y.; Asakawa, N. Stable Cationic Capillary Coating with Successive Multiple Ionic Polymer Layers for Capillary Electrophoresis. Anal. Chem. 1998, 70, 5272-5277.

(44) Barnes, J. M. CTAB: A New Disinfectant and Cleaning Agent. Lancet 1942, 239, 531-532.

(45) Hoogerheide, J. C. The Germicidal Properties of Certain Quarternary Ammonium Salts With Special Reference to CetylTrimethyl-Ammonium Bromide. J. Bacteriol. 1945, 49, 277-289.

(46) Sujatha, J.; Mishra, A. K. Effect of Ionic and Neutral Surfactants on the Properties of Phospholipid Vesicles: Investigation Using Fluorescent Probes. J. Photochem. Photobiol., A 1997, 104, 173-178.

(47) Lima, L. M. C.; Giannotti, M. I.; Redondo-Morata, L.; Vale, M.

L. C.; Marques, E. F.; Sanz, F. Morphological and Nanomechanical Behavior of Supported Lipid Bilayers on Addition of Cationic Surfactants. Langmuir 2013, 29, 9352-9361.

(48) Gómez-Graña, S.; Hubert, F.; Testard, F.; Guerrero-Martínez, A.; Grillo, I.; Liz-Marzán, L. M.; Spalla, O. Surfactant (Bi)Layers on Gold Nanorods. Langmuir 2012, 28, 1453-1459.

(49) Pantaler, E.; Kamp, D.; Haest, C. W. M. Acceleration of Phospholipid Flip-Flop in the Erythrocyte Membrane by Detergents Differing in Polar Head Group and Alkyl Chain Length. Biochim. Biophys. Acta, Biomembr. 2000, 1509, 397-408.

(50) Mukerjee, P.; Mysels, K. J. Critical Micelle Concentrations of Aqueous Surfactant Systems, NSRDS-NBS-36; National Bureau of Standards, 1971.

(51) Midura, R. J.; Yanagishita, M. Chaotropic Solvents Increase the Critical Micellar Concentrations of Detergents. Anal. Biochem. 1995, $228,318-322$. 